\title{
Physical Activity and Obesity Indicators: National Cross Sectional Study on Lebanese Adults
}

\author{
Soha Hourani ${ }^{1}$, Nagham Hamadeh ${ }^{2}$, Mohamad Al-Iskandarani ${ }^{3}$, Sarine El Daouk ${ }^{4}$, Maha Hoteit ${ }^{5}$ \\ 1,2,5 Department of Nutrition and Dietetics, Faculty of Public Health-Section I, Lebanese University-Beirut \\ ${ }^{3}$ Department of Mothers and Children Care Center, University Medical Center, Faculty of Public Health-Section I, \\ Lebanese University-Beirut \\ ${ }^{4}$ Department of Laboratory Sciences, Faculty of Public Health-Section I, Lebanese University-Beirut
}

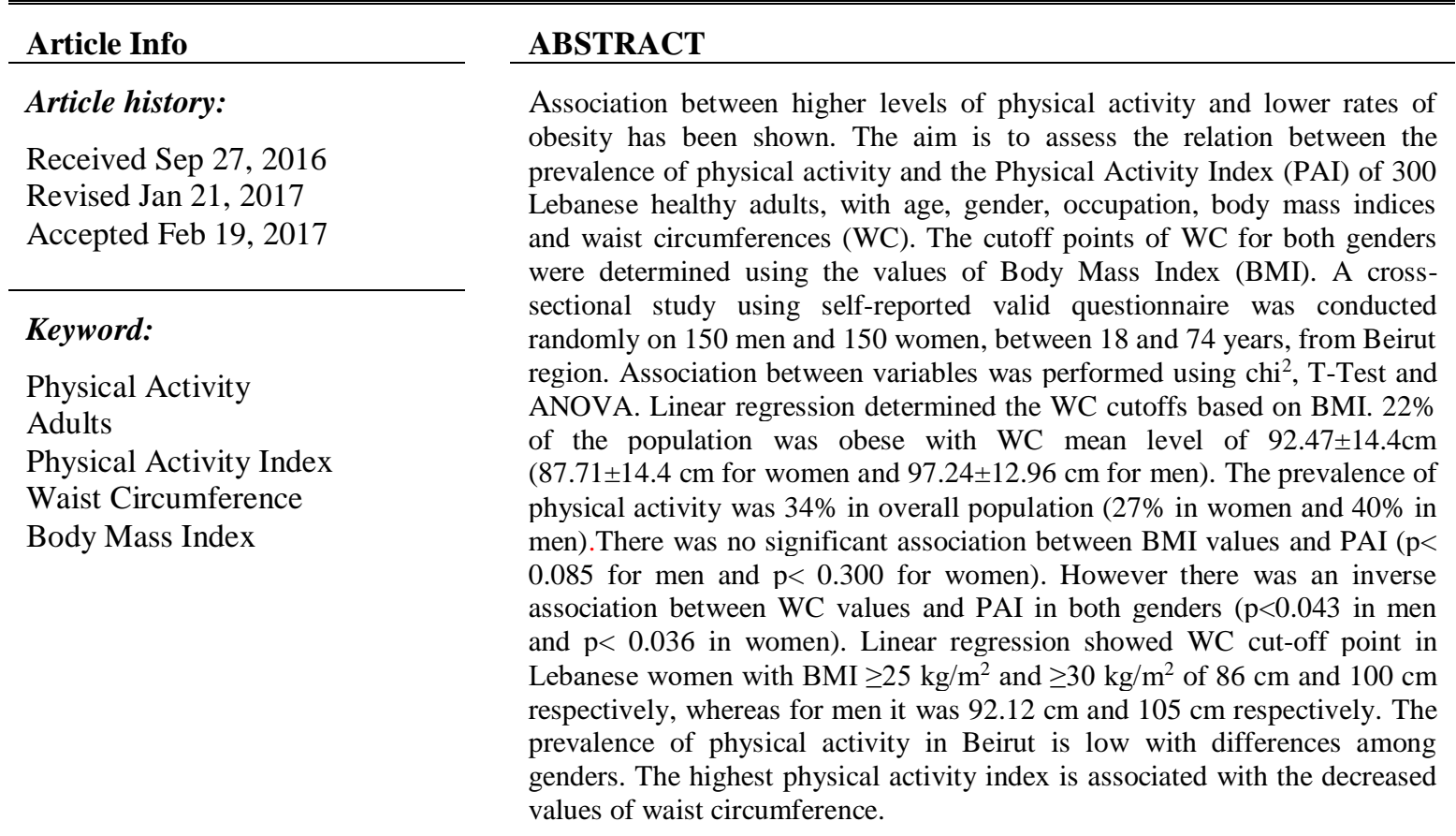

Copyright $(2017$ Institute of Advanced Engineering and Science. All rights reserved.

\section{Corresponding Author:}

Maha Hoteit,

Associate Professor, Department of Nutrition and Dietetics,

Faculty of Public Health-Section I,

Lebanese University-Beirut.

Email: maha_hoteit@hotmail.com/m.hoteit@ul.edu.lb

\section{INTRODUCTION}

Over the past 3 decades the obesity epidemic has spread inexorably across societies in all parts of the globe [1]. Obesity, an excess of body fat, has been well documented as key risk factor for a wide range of non-communicable diseases [2],[3]. Anthropometric measures have been widely used for body weight classification in humans. While Body Mass Index (BMI) has been shown to predict abdominal fat and abdominal subcutaneous fat, waist circumference has been shown to predict visceral fat, thus reinforcing the use of both BMI and waist circumference in clinical practice [4].

Physical activity appears to be the most variable component of energy expenditure and therefore has been the target of behavioral interventions to modify body weight. There is now a large body of evidence on the importance of physical activity in disease prevention [5]-[7]. 
In Lebanon, based on two national obesity surveys; results showed that $53 \%$ of people over 20 were overweight in 1997; a figure that continues to grow [8]. Another study was carried out in 2015 among the Lebanese population, revealed that $26.1 \%$ of the Lebanese people are obese [9]. One possible explanation is that the decline in the physical activity and the transition in the type of leisure activities seems a prime suspect in the growth of obesity in Lebanon. This survey aimed to assess the prevalence of physical activity and the physical activity index among healthy adults in Beirut region in relation to several factors; including age, gender and occupation. We also aimed to investigate the extent to which physical inactivity and sedentary lifestyle are associated with increased BMI and WC, and determining the cutoff points for the WC for both Genders based on BMI levels.

\section{RESEARCH METHOD}

\subsection{Sampling frame}

300 healthy Lebanese adults aged between 18 and 74 were randomly recruited from Beirut region. Sampling was done at three primary health care centers (Karagheusian center for child care, Mother and Child welfare, and Al Horj al Makassed center). The sites were chosen to reach the target community as much as possible trying to cover all categories of adult population of both genders with different educational levels. Adults were face to face interviewed and invited to participate in a self-reported questionnaire. If inclusion criteria were met, the questionnaire was handed to them to be completed. Individuals included in this study were healthy, aged between 18 and 74 years old, and only from the Lebanese nationality. Subjects could not be included in this study if they were taking medications affecting the appetite, those who have chronic diseases, also subjects with renal, liver, pancreatic insufficiencies, or any chronic inflammatory or infectious disease, hypertension, cardiovascular disease, diabetic, demented individuals, pregnant and lactating women were all excluded. Subjects who have active thyroid disease, or who were receiving thyroid hormone substitution were also excluded.

\subsection{Study Design} May, 2016.

This cross-sectional study was conducted at various hours of the week days between March and

\subsection{DATA Collection}

As the questionnaire contained personal information such as age groups, gender; Anthropometric data such as the weight, height, and waist circumference; confidentiality and complete anonymity were highly guaranteed. Each participant completed a self-reported questionnaire; age was classified into two categories: adults (18-64 years), and elderly (65-74 years). Anthropometric measurements were taken using standardized techniques and calibrated equipment's. The height was measured without shoes and recorded to the nearest $0.5 \mathrm{~cm}$ using a stadiometer. The weight was measured by a portable calibrated scale with bare feet. The waist circumference was measured using a measurement tape.

The General practice physical activity questionnaire (GPPAQ) was developed to provide a simple, 4-level Physical Activity Index (PAI) reflecting an individual's current physical activity, for use in general practice to decide when interventions to increase physical activity might be appropriate. Questions concerning walking, housework/childcare and gardening/DIY have been included, however they have not been shown to yield data of a sufficient reliability to contribute to an objective assessment of overall physical activity levels and are not included in the calculation of the PAI. Patients are classified into four categories (Active, Moderately active, moderately inactive and Inactive) based on the original EPIC index from which the GPPAQ was developed [10]. This questionnaire is a validated screening tool for use in primary care (GPPAQ 2008) [10] that is used to asses adults from 18 to 74 years old physical activity levels; provides a simple four level physical activity index(PAI) categorized participants as: active, moderately active, moderately inactive, and inactive.

This questionnaire is composed of three basic parts: the first one consisted of occupational activity (unemployed, office work, standing, hard work, and heavy lifting work). The second part consisted of questions regarding the previous week performed activities according to the type (sports such as swimming, biking, walking, housework, and gardening) and duration of the activity (none, less than one hour, one to three hours, and more than three hours). The third and final part was made up of a question on the type of the walking speed (slow, moderate, fast and very fast). This study was approved by the Ethical committee of the Lebanese University. The proposal of this cross sectional study was approved by the ethical committee at the Lebanese University. Study subjects were consented before participating. Funding: This research did not receive any specific grant from funding agencies in the public, commercial, or not-for-profit sectors. 


\subsection{Statistical analysis}

Continuous variables were analyzed using one way anova, chi $^{2}$ and Independent sample T-test analysis for associations between different variables. Also, regressions with odds ratios and $95 \%$ confidence intervals for the degree of association between variables were also used. Then, a stepwise backward logistic regression analysis was applied to test further the observed significant variables while controlling for colinearity. Linear regression test was used to determine the waist circumference cutoffs based on the BMI. A $p$-value below 0.05 denoted significance in differences. Data were analyzed using SPSS Version 23.

\section{RESULTS}

\subsection{Demographic and anthropometric characteristics}

The characteristics of our population are presented in Table 1. A total of 300 participants, 150 men and 150 women, randomly recruited in the study, in which $89.6 \%$ were aged between 18 and 64 years. The mean of the BMI of the studied population was $26.42 \pm 4.7 \mathrm{~kg} / \mathrm{m}^{2}(50.67 \%$ of women and $64 \%$ of men had a BMI $\left.\geq 25 \mathrm{~kg} / \mathrm{m}^{2}\right)$. The overall waist circumference mean value was $92.47 \pm 14.4 \mathrm{~cm}(87.71 \pm 14.4 \mathrm{~cm}$ for women and $97.24 \pm 12.96 \mathrm{~cm}$ for men). Men were older than women $(\mathrm{p}<0.006)$. Their anthropometric values (BMI and WC) were reported higher than in women $(\mathrm{p}<0.023$ and $\mathrm{p}<0.001$ respectively). In addition, more than $50 \%$ of women were unemployed and the majority of men recruited had an occupational work of standing or walking type. Using the PAI, only $27 \%$ of women were active compared to $40 \%$ of men $(\mathrm{p}<0.003)$.

Table 1. The Demographic, Anthropometric and Physical Activity Characteristics of The Population

\begin{tabular}{|c|c|c|c|c|}
\hline Study variables & Overall $(\mathrm{N}=300)$ & Women $(\mathrm{N}=150)$ & Men $(\mathrm{N}=150)$ & P-value $\dagger$ \\
\hline Age & $40.66 \pm 16.70$ & $38.00 \pm 15.20$ & $43.29 \pm 17.70$ & $<0.006$ \\
\hline \multicolumn{5}{|l|}{ Anthropometric Measurements } \\
\hline Height (m) & $1.67 \pm 0.09$ & $1.60 \pm 0.061$ & $1.76 \pm 0.07$ & $<0.001$ \\
\hline Weight & $74.85 \pm 15.80$ & $66.69 \pm 13.70$ & $83.00 \pm 13.40$ & $<0.001$ \\
\hline $\mathrm{BMI}\left(\mathrm{kg} / \mathrm{m}^{2}\right)$ & $26.42 \pm 4.70$ & $25.80 \pm 5.10$ & $27.05 \pm 4.10$ & $<0.023$ \\
\hline \multicolumn{5}{|l|}{ BMI Categories } \\
\hline Underweight & $2.7 \%$ & $4 \%$ & $1 \%$ & \multirow{3}{*}{$<0.089$} \\
\hline Normal & $40 \%$ & $45.3 \%$ & $35 \%$ & \\
\hline Overweight $\ddagger$ & $35.3 \%$ & $30.7 \%$ & $40 \%$ & \\
\hline Obesity $\S$ & $22 \%$ & $20 \%$ & $24 \%$ & \\
\hline Waist Circumference $(\mathrm{cm})$ & $92.47 \pm 14.40$ & $87.71 \pm 14.40$ & $97.94 \pm 12.90$ & $<0.001$ \\
\hline \multicolumn{5}{|l|}{ Physical activity } \\
\hline \multicolumn{5}{|l|}{ Occupational activity } \\
\hline Unemployed & $41 \%$ & $56.7 \%$ & $25.3 \%$ & \multirow{5}{*}{$<0.001$} \\
\hline Office work & $23.6 \%$ & $17.3 \%$ & $30 \%$ & \\
\hline Standing/Walking & $26.3 \%$ & $18 \%$ & $34.7 \%$ & \\
\hline Hard work & $7.7 \%$ & $8 \%$ & $7.3 \%$ & \\
\hline Heavy lifting & $1.4 \%$ & $0 \%$ & $2.7 \%$ & \\
\hline \multicolumn{5}{|l|}{ PAI $^{*}$} \\
\hline Active & $20.3 \%$ & $14 \%$ & $26.7 \%$ & \multirow{4}{*}{$<0.003$} \\
\hline Moderately active & $13.7 \%$ & $13.3 \%$ & $14 \%$ & \\
\hline Inactive & $43 \%$ & $52.7 \%$ & $33.3 \%$ & \\
\hline Moderately inactive & $23 \%$ & $20 \%$ & $26 \%$ & \\
\hline
\end{tabular}

Continuous variables are summarized as mean \pm Standard Deviation with statistical comparison using T-test. Categorical variables are summarized as count (\%) with statistical comparison using Chi-square.

$\dagger$ P value for difference between genders

†Overweight BMI between 25 to $29.9 \mathrm{~kg} / \mathrm{m}^{2}$

$\S$ Obesity if $\mathrm{BMI} \geq 30 \mathrm{~kg} / \mathrm{m}^{2}$

* Physical Activity Index PAI is calculated by combining the duration of exercise (sports and cycling) of participants per week with the type of occupation

\subsection{Variables association}

Table 2 shows a summary of the tests used to show associations between BMI or WC and occupational activities or PAI in overall subjects and by genders. In overall population, there was no significant association between occupational activities and WC $(p<0.200)$. However, when stratifying the data by gender, we observed that the highest WC and BMI were in men who works in offices $(\mathrm{p}<0.006$ and $\mathrm{p}<0.05$ respectively). Analyses in women show that the highest $\mathrm{WC}$ and BMI was observed in women who work hardly but data was only significant for BMI $(p<0.290$ and $p<0.03$ respectively). Post hoc analyses in 
men shows that those who have an office work had a high WC compared to those who have a hard work ( $\mathrm{p}$ <0.006). Also, subjects who have hard work had a low mean of WC compared to those the type of their work is standing or walking $(\mathrm{p}<0.021)$. When testing the association between the PAI and WC in both genders, analyses show that the highest WC was observed in inactive men and women $(\mathrm{p}<0.043$ and $\mathrm{p}<0.039$ respectively). Post hoc analyses show that inactive men and women had the highest WC compared to active men and women $(\mathrm{p}<0.001)$ (Data not shown).However, there was no association between PAI and BMI in overall population and when stratifying data by genders $(\mathrm{p}>0.05)$.

Table 2. Summary of Study Variables Associations

\begin{tabular}{|c|c|c|c|c|c|c|}
\hline Study variables & $\begin{array}{l}\text { Overall } \\
(\mathrm{N}=300)\end{array}$ & $\mathrm{P}$ value* & $\begin{array}{c}\text { Men } \\
(\mathrm{N}=150)\end{array}$ & $\mathrm{P}$ value* & $\begin{array}{l}\text { Women } \\
(\mathrm{N}=150)\end{array}$ & $\mathrm{P}$ value* \\
\hline & $\mathrm{WC}(\mathrm{cm})$ & & $\mathrm{WC}(\mathrm{cm})$ & & $\mathrm{WC}(\mathrm{cm})$ & \\
\hline \multicolumn{7}{|l|}{$\begin{array}{l}\text { Association between the Occupational } \\
\text { activity and the WC }\end{array}$} \\
\hline Unemployed & $90.66 \pm 15.00$ & & $96.34 \pm 14.00$ & & $88.12 \pm 14.80$ & \\
\hline Office work & $95.00 \pm 14.00$ & 0.200 & $100.29 \pm 10.50$ & 0.006 & $85.85 \pm 14.70$ & 0.290 \\
\hline Standing/walking & $93.95 \pm 14.70$ & & $98.44 \pm 13.60$ & & $85.30 \pm 13.20$ & \\
\hline \multicolumn{7}{|l|}{$\begin{array}{l}\text { Association between Occupational } \\
\text { activity and the BMI }\end{array}$} \\
\hline Unemployed & $26.16 \pm 4.90$ & & $26.87 \pm 4.00$ & & $25.84 \pm 5.30$ & \\
\hline Office work & $26.64 \pm 4.20$ & 0.900 & $27.70 \pm 3.30$ & 0.050 & $24.79 \pm 4.90$ & 0.030 \\
\hline Standing/walking & $26.67 \pm 4.80$ & & $27.43 \pm 4.90$ & & $24.92 \pm 4.70$ & \\
\hline Moderately active & $92.29 \pm 13.40$ & 0.100 & $96.43 \pm 12.90$ & 0.040 & $87.95 \pm 4.70$ & 0.030 \\
\hline Moderately inactive & $92.14 \pm 15.80$ & & $98.15 \pm 15.10$ & & $84.33 \pm 13.30$ & \\
\hline Inactive & $94.36 \pm 14.70$ & & $100.44 \pm 11.40$ & & $90.52 \pm 15.40$ & \\
\hline \multicolumn{7}{|l|}{ Association between PAI and the BMI } \\
\hline Active & $25.55 \pm 4.10$ & & $25.81 \pm 3.70$ & & $25.05 \pm 4.80$ & \\
\hline Moderately active & $26.25 \pm 4.50$ & 0.100 & $26.63 \pm 3.40$ & 0.080 & $25.84 \pm 5.50$ & 0.300 \\
\hline Moderately inactive & $26.00 \pm 5.00$ & & $27.25 \pm 5.20$ & & $24.51 \pm 4.30$ & \\
\hline Inactive & $27.00 \pm 4.80$ & & $28.04 \pm 3.60$ & & $26.47 \pm 5.40$ & \\
\hline
\end{tabular}

*p value was obtained by using ANOVA test.

\subsection{Waist circumference cut off points}

Using a linear regression test, the WC cutoff points were determined based on $\mathrm{BMI} \geq 25 \mathrm{~kg} / \mathrm{m}^{2}$ and $\geq 30 \mathrm{~kg} / \mathrm{m}^{2}$. WC cut-off point of $86 \mathrm{~cm}$ in women was the most sensitive to identify most subjects with a BMI $\geq 25 \mathrm{~kg} / \mathrm{m}^{2}$, whereas in men it was $92.12 \mathrm{~cm}$. The WC cut-off points corresponding to BMI $\geq 30 \mathrm{~kg} / \mathrm{m} 2 \mathrm{were}$ $100 \mathrm{~cm}$ in women and $105 \mathrm{~cm}$ in men as shown in Table 3.

Table 3. The WC Cut-Off Points for The Study Subjects Based On BMI $\geq 25 \mathrm{~kg} / \mathrm{m}^{2}$ and BMI $\geq 30 \mathrm{~kg} / \mathrm{m}^{2}$

\begin{tabular}{cccc}
\hline \multirow{2}{*}{ Group $(\mathrm{N}=300)$} & \multicolumn{3}{c}{ WC $(\mathrm{cm})$} \\
& $\begin{array}{c}\text { Abdominal obesity } \\
\text { BMI } \geq 25 \mathrm{~kg} / \mathrm{m}^{2}\end{array}$ & $\begin{array}{c}\text { Abdominal obesity } \\
\text { BMI } \geq 30 \mathrm{~kg} / \mathrm{m}^{2}\end{array}$ & p-value* \\
\hline Male $\quad(\mathrm{N}=150)$ & 92 & 105 & $<0.001$ \\
Female $(\mathrm{N}=150)$ & 86 & 100 & $<0.001$ \\
\hline
\end{tabular}

*P value was obtained using linear regression test

\section{DISCUSSION}

The results of the current study indicate a relatively high BMI (mean of $26.42 \pm 4.7 \mathrm{~kg} / \mathrm{m}^{2}$ ) and a considerable prevalence of obesity (22\%) among the Lebanese adults which was high in men compared to women. This result is in the same direction with a previous study that show an increasing prevalence of obesity between 1997 and 2009 (17.4\% and 28.2\%), respectively [8].

The prevalence of physically active participants was relatively low (34\%) and men were more active than women. This result is in accordance with the WHO report published in 2010 which shows that, globally, the $23 \%$ of adults aged over 18 years were insufficiently active (men $20 \%$ and women $27 \%$ ). The prevalence of insufficiently active people was $31 \%$ in the Eastern Mediterranean Region and $32 \%$ in the region of the 
America's while the prevalence was low in the South East Asia (15\%), and African regions (21\%). Across all regions, women were less active than men, with differences in prevalence between man and woman of $10 \%$ and greater in the Eastern Mediterranean region and the region of America's (WHO) [11] Also, our result is parallel to another study published in Lebanon which shows that $45 \%$ of the Lebanese adults were inactive [12]. This insufficiency in physical activity is influenced by several problematic behaviors, mainly marital status, obesity, smoking, health and mobility issues, personal motivation and social environments in which people live [13]. Inactivity among women was shown to be highest than in men that is likely to be rooted in the social norms and gender roles in traditional Arab societies, where women are seen mainly as child bearers. Confined to their homes, either because of social traditions or their pressing household duties women have little chance for sporting activities [14].

The relationship between the differences in occupational physical activity and the degree of obesity is still controversial. Our study shows that the highest WC and BMI were observed in men who work in offices and who are physically inactive. However, highest WC and BMI were found to be high in women who occupationally work hard and who are inactive. Our findings came hand in hand with many studies that show an inverse association between BMI, physical activity and occupational activity [2],[15]-[18]. This may be due to the occupational stress that may have a negative impact on individual eating behavior [19]-[21] leading to an increase in body weight and waist circumference accordingly. In one hand, other studies showed a decrease in the BMI with the increase in intensity of work [22]. On the other hand, Gutierrez-F. et al found no association after controlling for a number of obesity confounding factors [23].

Many anthropometric measures have been used to assess adiposity including BMI and WC. The WHO defines overweight as BMI $\geq 25 \mathrm{~kg} / \mathrm{m}^{2}$, obesity as BMI $\geq 30 \mathrm{~kg} / \mathrm{m}^{2}$ and central adiposity as WC $\geq 102$ $\mathrm{cm}$ in men and $\mathrm{WC} \geq 88 \mathrm{~cm}[24]$. However, such recommendations are derived mainly from the western populations, which cannot be applied to Arab population in the Middle East. This is the first national study to benchmark gender-specific cut-off points for waist circumference based on BMI for Lebanese adults.

In the present study, the WC cut-off points corresponding to BMI values of $30 \mathrm{~kg} / \mathrm{m}^{2}$ in both gender were reported to be higher $(100 \mathrm{~cm}$ in women and $105 \mathrm{~cm}$ in men) than other studies conducted in Iran $(99.5$ $\mathrm{cm}$ for men and $94.25 \mathrm{~cm}$ for women) [25], and other countries such as Turkey (100 cm for men and $90 \mathrm{~cm}$ for women) [26]. In addition, the waist circumference cut-off for BMI $\geq 25 \mathrm{~kg} / \mathrm{m}^{2}$ of the Lebanese studied sample was also higher ( $92 \mathrm{~cm}$ for men and $86 \mathrm{~cm}$ for women) compared to Tunisian population cutoff (85 $\mathrm{cm}$ for men and $79 \mathrm{~cm}$ for women) [27] and Turkish population (90 cm for men and $80 \mathrm{~cm}$ for women) (Alper S et al 2013) [26]. These differences correspond to the heterogeneity among different populations and ethnics groups. The target WC associated with increased CV risk and normal levels should be defined for each population.

\subsection{Strengths and Limitations}

To our knowledge, this is the first national study reporting the WC cutoffs in Lebanese men and women based on their BMI. Also, it is the first national study describing the association between physical activity and occupational activity pattern in association with obesity indicators. However, our study has a number of limitations as the cross-sectional nature of the study and the relative low sample size. Also, it is not a population-based or representative study. Understanding exercise motivation and how motivation can change among individuals over time would be better comprehended if a longitudinal design was employed. This study did not take into account the different socio-economical levels that might have impacted participant motivation to exercise. The data are limited to the Lebanese population and may not represent the WC cutoff values required for definition of abdominal obesity in other Middle Eastern countries. The present study did not have direct measures of body fatness or fat distribution. The outcome of this study relied on self-report, thus the extent to which participants were inclined to provide socially desirable responses is not fully known.

\section{CONCLUSION}

The findings of the present study provide alarming evidences for health professionals and policy makers about the high prevalence of abdominal obesity in Lebanon despite the raising concerns regarding the obesity problem in the country, adding that our population is almost inactive. Preventive and treatment strategies, notably in women, are urgently needed to prevent overweight and obesity and promote weight maintenance and weight loss and address the health burden of obesity. In view of the fact that unhealthy lifestyle habits, notably, the sedentary lifestyles in our community, are among the major threats contributing to the challenge, more severe efforts should be incorporated with the existing health promotion programs in order to decrease the possible epidemic of obesity and obesity-related chronic diseases in the near future. 


\section{LIST OF ABBREVIATIONS}

BMI: Body Mass Index

WC: Waist Circumference

GPPAQ: General Practice Physical Activity Questionnaire

PAI: Physical Activity Index

WHO: World Health Organization

$\mathrm{CV}$ : Cardiovascular

\section{ACKNOWLEDGMENT}

The authors would like to thank the 3 Primary Health Care centers affiliated with the Lebanese

Ministry of Public Health for assisting in data collection and subject's recruitments.

\section{REFERENCES}

[1] A. Luke and Richard C., "Physical activity does not influence obesity risk: time to clarify the public health message," Int. J. Epidemiol, 2013.

[2] Choi B., et al., "Sedentary work, low physical job demand, and obesity in US workers," Am J Ind Med, 2010.

[3] B. Moghimi, et al., "Overweight and Obesity and Related Factors in Urban Iranian Population Aged between 20 to 84 Years," Ann Med Health Sci Res, 2013.

[4] Akpinar E., et al., "Which is the best anthropometric technique to identify obesity: body mass index, waist circumference or waist-hip ratio?" Coll Antropol, vol. 31, pp. 387-93, 2007.

[5] P. Kokkinos, et al., "Physical Activity, Health Benefits, and Mortality Risk," ISRN Cardiol, 2012.

[6] Mora S., et al., "Physical Activity and Reduced Risk of Cardiovascular Events: Potential Mediating Mechanisms," Circulation, 2007.

[7] Ulf E., et al., "Physical Activity and Metabolic Risk in Individuals with a Family History of Type 2 Diabetes," $A D A, 2007$.

[8] L. Nasreddine, et al., "Trends in overweight and obesity in Lebanon: evidence from two national cross-sectional surveys (1997 and 2009)," BMC Public Health, 2012.

[9] M. C. Chamieh, et al., "Diet, physical activity and socio-economic disparities of obesity in Lebanese adults: findings from a national study," BMC Public Health, 2015.

[10] N. Heron, et al., "Physical activity assessment in practice: "a mixed methods study of GPPAQ use in primary care," BMC Family Practice, 2014.

[11] World health organization, 2016. http://www.who.int/gho/ncd/risk_factors/physical_activity_text/en/

[12] M. Al-Tannir, et al., "Prevalence of Physical Activity among Lebanese Adults: A Cross-Sectional Study," Journal of Physical Activity and Health, vol. 6, pp. 315-320, 2009.

[13] P. T. Katzmarzyk, "Physical Activity, Sedentary Behavior, and Health: Paradigm Paralysis or Paradigm Shift?" $A D A, 2010$.

[14] Dennis V., et al., "Obesity in older adults: technical review and position statement of the American Society for Nutrition and NAASO, The Obesity Society," Am J Clin Nutr, vol/issue: 82(5), pp. 923-934, 2005.

[15] Livingstone M. B., et al., "Physical activity patterns in a nationally representative sample of adults in Ireland," Public Health Nutr, vol/issue: 4(5A), pp. 1107-16, 2001.

[16] Sulemana H., et al., "Relationship between physical activity and body mass index in adolescents," Med Sci Sports Exerc., 2006.

[17] H. Tilaki and Heidari B., "Prevalence of obesity, central obesity and the associated factors in urban population aged 20-70 years, in the north of Iran: a population-based study and regression approach," Obes Rev., 2007.

[18] A. Jääskeläinen, et al., "Association between occupational psychosocial factors and waist circumference is modified by diet among men," European Journal of Clinical Nutrition, 2015.

[19] Sandrine D., et al., "Work-related and Dietary Factors Associated with Weight Gain over the Period of Employment in Paramedics," Occupational Medicine \& Health Affair, 2014.

[20] Paul A., et al., "Work, Obesity, and Occupational Safety and Health," Am J Public Health, 2007.

[21] Kouvonen A., et al., "Relationship between work stress and body mass index among 45,810 female and male employees," Psychosom Med, 2005.

[22] Barberio A. and McLaren L., "Occupational physical activity and body mass index (BMI) among Canadian adults: does physical activity at work help to explain the socio-economic patterning of body weight?" Can J Public Health, vol/issue: 102(3), pp. 169-73, 2011.

[23] Gutie'rrez, et al., "Work-related physical activity is not associated with body mass index and obesity," Obes Res, 2002.

[24] Waist circumference and waist-hip ratio: report of a WHO expert consultation, Geneva, 8-11 December 2008.

[25] Ramin H., et al, "The Appropriate Waist Circumference Cut-off for Iranian Population," Acta Med IndonesIndones J Intern Med, vol/issue: 42(4), pp. 209-15, 2010.

[26] A. Sonmez, et al., "Waist Circumference Cutoff Points to Predict Obesity, Metabolic Syndrome," Cardiovascular Risk in Turkish Adults, 2013.

[27] Bouguerra R., et al., "Waist circumference cut-off points for identification of abdominal obesity among the tunisian adult population," Diabetes Obes Metab., 2007. 